\title{
Presentation and Management of a Postoperative Spinal Pseudomeningocele
}

\author{
Sindhuja Surapaneni · Jamal Hasoon - Vwaire Orhurhu • \\ Omar Viswanath · Alan D. Kaye - Cyrus Yazdi · Aner Musa • \\ Ivan Urits
}

Received: September 19, 2019 / Published online: November 18, 2019

(C) The Author(s) 2019

Keywords: Cerebrospinal fluid; Headache; MRI; Pseudomeningocele

Enhanced Digital Features To view enhanced digital features for this article, go to https://doi.org/10.6084/ m9.figshare.10247621.

S. Surapaneni $(\bowtie) \cdot J$. Hasoon · C. Yazdi · A. Musa · I. Urits

Department of Anesthesia, Critical Care, and Pain Medicine, Beth Israel Deaconess Medical Center,

Harvard Medical School, Boston, MA, USA

e-mail: ssurapan@bidmc.harvard.edu

V. Orhurhu

Department of Anesthesia, Critical Care and Pain Medicine, Division of Pain, Massachusetts General

Hospital, Harvard Medical School, Boston, MA, USA

O. Viswanath

Valley Anesthesiology and Pain Consultants-

Envision Physician Services, Phoenix, AZ, USA

O. Viswanath

Department of Anesthesiology, University of

Arizona College of Medicine-Phoenix, Phoenix, AZ, USA

O. Viswanath

Department of Anesthesiology, Creighton

University School of Medicine, Omaha, NE, USA

A. D. Kaye

Department of Anesthesiology, Louisiana State

University Health Sciences Center, New Orleans, LA, USA

\section{Key Summary Points}

A pseudomeningocele, or a collection of cerebrospinal fluid, typically presents as a postoperative complication, and can be asymptomatic and resolve spontaneously, though some present with headaches, low back pain, or radicular symptoms.

The best management of spinal pseudomeningocele is debated, but important considerations include nerve root involvement, pseudomeningocele size and location.

Revision surgery and dural tear repair may be an important option in symptomatic patients. In patients who are asymptomatic, nonsurgical management can result in spontaneous resolution of the pseudomeningocele with scar formation over time.

\section{CASE}

The aim of this case is to highlight the importance of radiographic determination of the presence of a pseudomeningocele and the subsequent constellation of symptoms. A 


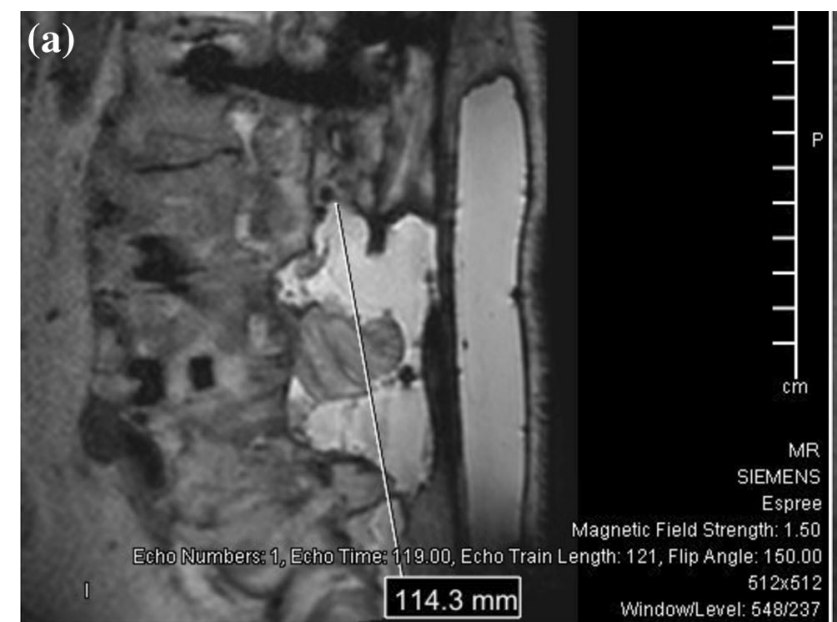

Fig. 1 a A T2-weighted sagittal magnetic resonance image demonstrating the extent of the pseudomeningocele. A cranio-caudal measurement of the subfascial component of the pseudomeningocele is included. b A T2-weighted

pseudomeningocele, or a collection of cerebrospinal fluid (CSF), typically presents as a postoperative complication [1]. Spinal pseudomeningoceles can be asymptomatic and resolve spontaneously, though some present with headaches, low back pain, or radicular symptoms [2]. These are the radiographic findings of a female with chronic low back pain status post multiple spinal surgeries, most recently an L4-L5 revision laminectomy complicated by a CSF leak. She presented with paresthesia's, subjective weakness, and an occipital headache. An MRI revealed a $4.5 \times 4.8 \times 11.4-\mathrm{cm}$ CSF collection communicating with a $2.8 \times 11.7 \times 14-\mathrm{cm}$ subcutaneous soft tissue fluid collection (Fig 1a, b). A small defect at the level of L5-S1 connecting the spinal canal to a posterior fluid collection was determined.

The best management of spinal pseudomeningocele is debated, but important considerations include nerve root involvement, pseudomeningocele size and location. Revision surgery and dural tear repair may be an important option in symptomatic patients. In patients who are asymptomatic, nonsurgical management can result in spontaneous resolution of the pseudomeningocele with scar

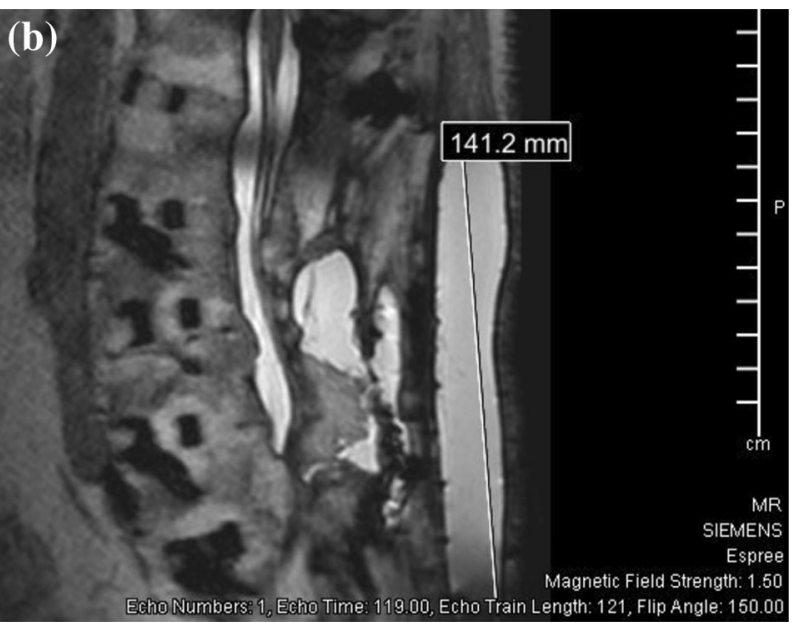

sagittal magnetic resonance image demonstrating the extent of the pseudomeningocele. A cranio-caudal measurement of the subcutaneous component of the pseudomeningocele is included

formation over time [3, 4]. Informed consent for publication was obtained from the participant.

\section{ACKNOWLEDGEMENTS}

Funding. No funding or sponsorship was received for this study or publication of this article.

Authorship. All named authors meet the International Committee of Medical Journal Editors (ICMJE) criteria for authorship for this article, take responsibility for the integrity of the work as a whole, and have given their approval for this version to be published.

Disclosures. Sindhuja Surapaneni, Jamal Hasoon, Vwaire Orhurhu, Omar Viswanath, Cyrus Yazdi, Aner Musa, and Ivan Urits have nothing to disclose. Alan D. Kaye is a member of the journal's editorial board.

Compliance with Ethics Guidelines. Informed consent for publication was obtained from the participant. 
Open Access. This article is distributed under the terms of the Creative Commons Attribution-NonCommercial 4.0 International License (http://creativecommons.org/licenses/ by-nc/4.0/), which permits any noncommercial use, distribution, and reproduction in any medium, provided you give appropriate credit to the original author(s) and the source, provide a link to the Creative Commons license, and indicate if changes were made.

\section{REFERENCES}

1. Hawk MW, Kim KD. Review of spinal pseudomeningoceles and cerebrospinal fluid fistulas. Neurosurg Focus. 2000;9(1):e5.
2. Aldrete JA, Ghaly R. Postlaminectomy pseudomeningocele. An unsuspected cause of low back pain. Reg Anesth. 1996;20:75-9.

3. Weng YJ, Cheng CC, Li YY, Huang TJ, Hsu RW. Management of giant pseudomeningoceles after spinal surgery. BMC Musculoskel Disord. 2010;11:53. https://doi.org/10.1186/1471-2474-1153.

4. Woodroffe RW, Nourski KV, Helland LC, Walsh B, Noeller J, Kerezoudis P, Hitchon PW. Management of iatrogenic spinal cerebrospinal fluid leaks: a cohort of 124 patients. Clin Neurol Neurosurg. 2018;170:61-6. 